\title{
Exercise Rehabilitation after Anterior Cruciate Ligament Reconstruction
}

\author{
Keun Ok $\mathrm{An}^{1 *}$ \\ 'Sports and Health Care Major, College of Humanities and Social Sciences, Korea National University of Transportation, Chungju, \\ Republic of Korea
}

\begin{abstract}
OBJECTIVES: Exercise rehabilitation after anterior cruciate ligament (ACL) reconstruction has changed dramatically in recent years. In this review, we discuss recent changes in exercise programs related to ACL rehabilitation.

METHODS: We conducted a literature review of recently published articles related exercise programs after ACL reconstruction.

RESULTS: The accelerated rehabilitation program, which allows patients to achieve full extension of the knee early in the postoperative period, is now a widely practiced rehabilitation program. A prospective study of rehabilitation programs after ACL reconstruction showed that early joint exercises do not interfere with the healing of grafts. Instead, they alleviate pain, thereby reducing the negative impact. Moreover, according to several biomechanical studies, open kinetic chain exercises are potentially disadvantageous to knee stability. There is no evidence that early weight bearing results in weakening of graft distraction or internal fixation compared with delayed weight bearing.

CONCLUSIONS: In conclusion, prevention of ACL injuries and rehabilitative exercise training can help to achieve optimal exercise performance while avoiding the risk of sports-related injury.
\end{abstract}

KEY WORDS: Exercise; Rehabilitation; ACL reconstruction; Sports injury

(c) The Author(s). 2017 Open Access This is an open-access article distributed under the terms of the Creative Commons Attribution License (http://creativecommons.org/licenses/by/4.0/), which permits unrestricted use, distribution, and reproduction in any medium, provided the original work is properly cited.

\section{INTRODUCTION}

Exercise rehabilitation after anterior cruciate ligament (ACL) reconstruction has changed dramatically in recent years. Previous exercise rehabilitation programs required a period of 9-12 months to return to the sports field, because of the perceived need for a period of 8-10 weeks to perform limited range of motion (ROM) and full weight bearing. However, after Shelbourne et al. [1,2] introduced the accelerated rehabilitation program, the ability to re-

\footnotetext{
*Correspondence: Keun Ok An (koan@ut.ac.kr)

Sports and Health Care Major, College of Humanities and Social Sciences, Korea National University of Transportation, 50 Daehak-ro, Chungju-si, Chungbuk 27469, Republic of Korea.

Received: May 10, 2017; Accepted: June 2, 2017; Published: June 3, 2017
}

turn to the sports field within 4-6 months after ACL reconstruction became practical due to the implementation of immediate exercise rehabilitation that facilitated recovery of ROM and weight bearing (Table 1). In this review, we discuss recent changes in exercise programs related to ACL rehabilitation.

\section{Accelerated rehabilitation program}

The accelerated rehabilitation program, which allows patients to achieve full extension of the knee early in the postoperative period, is now a widely practiced rehabilitation program. These rehabilitation programs include restoration of ROM and weight bearing, early edema reduction, protection of the ACL replacement graft through closed kinetic chain exercises rather than open kinetic 
Table 1. Accelerated rehabilitation program

\begin{tabular}{|c|c|}
\hline Time after reconstruction & Rehabilitation program \\
\hline Day 1 & $\begin{array}{l}\text { Continuous passive motion (CPM), rigid knee immobilizer in full extention for walking, weight bearing as tolerated without } \\
\text { crutches }\end{array}$ \\
\hline 2-3 days & $\mathrm{CPM}$, passive range of motion ( $\mathrm{ROM}) 0^{\circ}$ to $90^{\circ}$ (emphasis on full extension), weight bearing as tolerated without crutches \\
\hline 2-4 day & $\begin{array}{l}\text { Discharge from hospital; CPM at home. } \\
\text { Note: Prerequisite to discharge is 1) satisfactory pain management, 2) full extention symmetical to non-operated knee, 3) } \\
\text { able to do SLR for leg control, 4) full weight bearing with or without cruches }\end{array}$ \\
\hline 7-10 day & $\begin{array}{l}\text { ROM terminal extension, prone hangs ( } 2 \text { pounds) if patient has not achieved full extension, towel extension, wall slide, heel } \\
\text { slides, active-assisted flexion, strengthening-knee, bends, step-ups, calf raise; weight bearing-partial to full weight bearing; } \\
\text { gradual elimination of required use of knee immobilizer }\end{array}$ \\
\hline 2-3 weeks & $\begin{array}{l}\text { ROM }\left(0^{\circ}-110^{\circ}\right) \text {, unilateral knee bends, step-ups, calf raises, Stair Master } 4000 \text {, weight room activities; leg press, quarter squats } \\
\text { and calf raises in the squat rack, stationary bicycling, swimming, custom-made functional knee brace with no preset limits (to } \\
\text { be used at all times out of the home for the next 4weeks) }\end{array}$ \\
\hline $5-6$ weeks & $\begin{array}{l}\operatorname{ROM}\left(0^{\circ}-130^{\circ}\right) \text {, isokinetic evaluation with } 20^{\circ} \text { block at } 180 \text { and } 240 \mathrm{deg} / \mathrm{sec} \text {. When strength is } 70 \% \text { or greater than the oppo- } \\
\text { site un-operated knee, the patient can being lateral shuttles, cariocas, light jogging, jumping rope, agility drills, weight room } \\
\text { activities, stationary bicycling, and swimming. Note: Functional brace discontinued (except for sports activities) when muscle } \\
\text { tone and strength are sufficient. }\end{array}$ \\
\hline 10 weeks & Full ROM; isokinetic evaluation at 60, 180, and $240 \mathrm{deg} / \mathrm{sec}, \mathrm{KT} 1000$, increased agility workouts, sport-specific activities \\
\hline 16 weeks & Isokinetic evaluation, KT 1000, increased agility workouts \\
\hline 4-6 months & $\begin{array}{l}\text { Return to full sports participation (if patient has met, criteria of full ROM, no effusion, good knee stability, and completed the } \\
\text { running program) }\end{array}$ \\
\hline
\end{tabular}

Shelbourne KD \& Nitz P. Accelerated rehabilitation after anterior cruciate ligament reconstruction. J Orthop Sports Phys The, $1992 ; 15(6): 256-64$.

chain exercises, restoration of dynamic stability of the joint through premature hamstring strengthening, proprioceptive functional training and neuromuscular rehabilitation, muscle strength training, and agility training [1]. Preferably, this accelerated rehabilitation exercise program is implemented in an individualized manner, according to the condition of the patient.

A prospective study of rehabilitation programs after ACL reconstruction showed that early joint exercises do not interfere with the healing of grafts or prevent the limitation of ROM. Instead, they alleviate pain, thereby reducing the negative impact [3-7]. Moreover, Jørgensen \& Thomsen [8] reported that there is no evidence that early weight bearing results in weakening of graft distraction or internal fixation compared with delayed weight bearing.

\section{Open kinetic chain and closed kinetic chain exercises}

In one prospective study, Bynum et al. [9] reported anterior instability one year postoperatively and decreased patient satisfaction with open kinetic chain exercises compared with closed kinetic chain exercises [9]. However, other studies observed no difference between open and closed kinetic chain exercises [10-12]. According to these biomechanical studies, open kinetic chain exercises are potentially disadvantageous to knee stability, but the effects of their application remains controversial. Some prospective randomized controlled studies have compared home-based exercise rehabilitation with hospital-based rehabilitation centers and other rehabilitation centers. Although researchers were more involved, there was no significant difference in outcomes between the two groups [13-16].

\section{Returning to the sports field}

The recommended time for returning to the sports field has varied significantly based on largely different findings of various researchers. However, the researchers suggest the same preconditions for returning to the sports scene after surgery, such as restored ROM, disappearance of joint edema, isokinetic musculoskeletal test (unaffected side), muscle strength of quadriceps recovered to $80-90 \%$ full strength, muscle strength of hamstring recovered to $85-90 \%$ full strength, uninvolved in one-leg hop test, and the elapses after surgery during the 9-month postoperative period [17]. So far, we have discussed how rehabilitation is most effective after ACL injury; however, the innovative paradigm of future rehabilitation programs will require the development of preventive programs to prevent ACL injuries in advance.

\section{ACL injury prevention programs}

ACL injury prevention programs consist of programs for improving muscular training and exercise performance such as plyometrics, strength training, balance training, and resistance training [18]. The trained athletes are in- 
structed by the trainer to perform biomechanically correct motions and receive feedback during and after the training [18]. The training protocol focuses on the practice of correct training techniques. Especially at the beginning of training, exercises should be performed with correct form. The trainer must be familiar with the correct training exercises and constantly encourage the athletes to perform the exercises with precise form. If the players are tired and unable to perform the exercises with correct form, the exercise training should be stopped.

\section{CONCLUSIONS}

In conclusion, prevention of ACL injuries and rehabilitative exercise training can help to achieve optimal exercise performance while avoiding the risk of sports-related injury.

\section{Conflicts of interest}

The authors declare no conflicts of interest.

\section{REFERENCES}

[1] Shelbourne K, Nitz P. Accelerated rehabilitation after anterior cruciate ligament reconstruction. Am J Sports Med 1990 18: 292-9. https://doi.org/10.1177/036354659001800313

[2] Shelbourne K, Nitz P. Accelerated rehabilitation after anterior cruciate ligament reconstruction. J Orthop Sports Phys Ther 1992; 15:256-64. https://doi.org/10.2519/jospt.1992.15.6.256

[3] Häggmark T, Eriksson E. Cylinder or mobile cast brace after knee ligament surgery. A clinical analysis and morphologic and enzymatic studies of changes in the quadriceps muscle. Am J Sports Med 1979; 7:48-56. https://doi.org/10.1177/036354657900700111

[4] Henriksson M, Rockborn P, Good L. Range of motion training in brace vs. plaster immobilization after anterior cruciate ligament reconstruction: a prospective randomized comparison with a 2-year follow-up. Scand J Med Sci Sports 2002; 12:73-80. https://doi.org/10.1034/j.1600-0838.2002.120203.x

[5] Noyes F, Mangine R, Barber S. Early knee motion after open and arthroscopic anterior cruciate ligament reconstruction. Am J Sports Med 1987; 15:149 -60. https://doi.org/10.1177/036354658701500210

[6] Richmond J, Gladstone J, MacGillivray J. Continuous passive motion after arthroscopically assisted anterior cruciate ligament reconstruction: comparison of short- versus long-term use. Arthroscopy 1991; 7:39 -44. https://doi.org/10.1016/0749-8063(91)90076-A

[7] Rosen M, Jackson D, Atwell E. The efficacy of continuous passive motion in the rehabilitation of anterior cruciate ligament reconstructions. Am J Sports Med 1992; 20:122-7. https://doi.org/10.1177/036354659202000205

[8] Jørgensen U, Thomsen H. Behavior of the graft within the bone tunnels following anterior cruciate ligament reconstruction, studied by cinematic magnetic resonance imaging. Knee Surg Sports Traumatol Arthrosc 2000; 8:32-5. https://doi.org/10.1007/s001670050007

[9] Bynum E, Barrack R, Alexander A. Open versus closed chain kinetic exercises after anterior cruciate ligament reconstruction. A prospective randomized study. Am J Sports Med 1995;23:401-6. https://doi.org/10.1177/036354659502300405

[10] Perry M, Morrissey M, King J, et al. Effects of closed versus open kinetic chain knee extensor resistance training on knee laxity and leg function in patients during the 8- to 14-week post-operative period after anterior cruciate ligament reconstruction. Knee Surg Sports Traumatol Arthrosc 2005;13:357-69. https://doi.org/10.1007/s00167-004-0568-7

[11] Hooper D, Morrissey M, Drechsler W, et al. Open and closed kinetic chain exercises in the early period after anterior cruciate ligament reconstruction. Improvements in level walking, stair ascent, and stair descent. Am J Sports Med 2001;29:167-74. https://doi.org/10.1177/03635465010290020901

[12] Mikkelsen C, Werner S, Eriksson E. Closed kinetic chain alone compared to combined open and closed kinetic chain exercises for quadriceps strengthening after anterior cruciate ligament reconstruction with respect to return to sports: a prospective matched follow-up study. Knee Surg Sports Traumatol Arthrosc 2000; 8:337-42. https://doi.org/10.1007/s001670000143

[13] Fischer D, Tewes D, Boyd J, et al. Home based rehabilitation for anterior cruciate ligament reconstruction. Clin Orthop Relat Res 1998; 347:194-9. PMID: 9520889

[14] Grant J, Mohtadi N, Maitland M, et al. Comparison of home versus physical therapy-supervised rehabilitation programs after anterior cruciate ligament reconstruction: a randomized clinical trial. Am J Sports Med 2005; 33:1288-97. https://doi.org/10.1177/0363546504273051

[15] Schenck R, Blaschak M, Lance E, et al. A prospective outcome study of rehabilitation programs and anterior cruciate ligament reconstruction. Arthroscopy 1997; 13:285-90. https://doi.org/10.1016/S0749-8063(97)90022-0

[16] Beard DJ, Dodd CA. Home or supervised rehabilitation following anterior cruciate ligament reconstruction: a randomized controlled trial. J Orthop Sports Phys Ther 1998; 27:134-43. 
https://doi.org/10.2519/jospt.1998.27.2.134

[17] Paulos L, Stern j. Rehabilitation after anterior cruciate ligament surgery. New York: Raven Press 1993.

[18] Myer G, Ford K, Palumbo J, et al. Neuromuscular training improves performance and lower-extremity biomechanics in female athletes. J Strength Cond Res 2005; 19:51-60. https://doi.org/10.1519/13643. 